Vol 12, Issue 6, 2019

Online - 2455-3891

Print - 0974-2441

$\underline{\text { Research Article }}$

\title{
TOTAL PHENOLIC CONTENT AND FREE RADICAL SCAVENGING ACTIVITY OF MIMUSOPS ELENGI L. LEAVES
}

\author{
VINEETA SINGH*, PANDEY VN \\ Department of Botany, Experimental Botany and Nutraceutical Laboratory, Deen Dayal Upadhyay Gorakhpur University, Gorakhpur, \\ Uttar Pradesh, India. Email: vnpgu@yahoo.co.in
}

Received: 29 March 2019, Revised and Accepted: 10 May 2019

\section{ABSTRACT}

Objective: The motive of the current study was to find out the total phenolic content (TPC) and free radical scavenging (FRS) activity of various solvent extracts of leaves.

Methods: Leaves powder was subjected to extraction with different solvents, namely methanol, methanol 80\%, ethanol, ethanol 80\%, chloroform, acetone, aqueous, and ethyl acetate. Different concentrations of extracts were evaluated for FRS activity by 2,2-diphenyl-1-picrylhydrazyl (DPPH) assay and TPC spectrophotometrically by Folin-Ciocalteu method.

Results: The results clearly indicate that inhibition concentration of DPPH by leaf extracts was higher in methanol (inhibitory concentration $50=8.74$ ) followed by ethanol > ethanol $80 \%>$ methanol $80 \%>$ acetone $>$ aqueous > chloroform > ethyl acetate. TPC was higher in methanol $(6.2 \pm 0.01$ mg gallic acid equivalent/g) followed by ethanol > methanol $80 \%>$ acetone $>$ aqueous $>$ ethyl acetate $>$ ethanol $80 \%>$ chloroform. A significant correlation $\left(y=0.6265 x+42.91 R^{2}=0.9756\right)$ exists between TPC and FRS activity of methanolic extract.

Conclusion: The finding revealed that methanolic extract of leaves contains a significant amount of FRS activity and phenolic compounds compared to other extracts.

Keywords: Mimusops elengi L., Total phenolic content, Free radical scavenging activity, 2,2-diphenyl-1-picrylhydrazyl assay, Folin-Ciocalteu.

(C) 2019 The Authors. Published by Innovare Academic Sciences Pvt Ltd. This is an open access article under the CC BY license (http://creativecommons. org/licenses/by/4. 0/) DOI: http://dx.doi.org/10.22159/ajpcr.2019.v12i6.33282

\section{INTRODUCTION}

Cellular destruction or oxidative impairment arising from reactive oxygen species (ROS) or free radicals now appears the core mechanism underlying endless of human disorders, normal aging, inflammation, autoimmune pathologies, digestive system disorders, and diabetes. Free radical and ROS are generated through normal metabolism of drugs, environmental chemicals, and other xenobiotics as well as endogenous chemicals, especially stress hormones [1]. ROS easily react with macromolecules of crucial biological significance (DNA, lipids, and protein) and destroy their function and structure [2]. Antioxidants are those substances which possess the ability to protect the organism from damage caused by free radical-induced oxidative stress $[3,4]$. At present, the most commonly used antioxidants are butylated hydroxyanisole (BHA), butylated hydroxytoluene (BHT), propyl gallate, and tert-butyl hydroquinone. However, they are suspected of being responsible for liver damage and carcinogenesis in laboratory animals. Therefore, the development and utilization of more effective antioxidants of natural origin are desired [5].

Naturally occurring antioxidant compounds, from the plant, have been identified as free radical or reactive oxygen scavengers. They have gained significant interest from researchers due to their broad range effects and effectiveness. Many bioactive compounds (phenols, flavonoids, carotenes, etc.) present in foods are highly responsible for the health effects. These bioactive compounds play a major role as antioxidants due to the presence of hydroxyl substituents and their aromatic structure, which enables them to scavenge free radicals $[6,7]$.

Mimusops elengi L. (Sapotaceae) possess powerful health-giving properties. It is used in traditional system of medicine. The decoction of leaves is used as a mouth cleansing to prevent and cure the disease of gum and teeth. The paste of leaf is used in the healing of wounds $[8,9]$. Leaves are the rich sources of bioactive compounds, namely tannins, saponins, terpenoids, and flavonoids [10]. Besides this, it is also necessary to investigate its antioxidant properties. Therefore, the intention of this study was to evaluate the TPC and FRS of leaves extracts and to determine the relation between TPC and FRS.

\section{METHODS}

\section{Chemicals}

BHT, BHA, ascorbic acid, gallic acid, and 2,2-diphenyl-1-picrylhydrazyl (DPPH) were purchased from Sigma Chemical Co. (St. Louis, MO, USA); Folin-Ciocalteu reagent, sodium bicarbonate, Whatman No. 1 filter paper, and high-performance liquid chromatography grade solvents (methanol, ethanol, acetone, chloroform, ethyl acetate, and diethyl ether) were purchased from E-Merck (India) Ltd., Mumbai, India. Only distilled deionized water was used.

\section{Sample preparation}

Collection of fresh leaves was done from Deen Dayal Upadhyay (DDU) Gorakhpur University campus. The leaves were cleaned under tap water and dried under shade. The desiccated leaves were then ground into a fine powder using a mechanical grinder and kept in a sealed container.

\section{Extraction}

Leaves powder was weighed in a selected quantity and extracted using various solvents (methanol, methanol 80\%, ethanol, ethanol $80 \%$, acetone, ethyl acetate, chloroform, and distilled water). After extraction, solvents were evaporated. The crude extracts thus obtained were used for the determination of total phenolic content (TPC) and free radical scavenging (FRS) activity.

\section{Determination of phenolic content}

Phenolic content was determined by the procedure of Wu etal.,2007 [11]. The powder (100 g) was defatted using diethyl ether as the solvent. 
The residue was dried in an oven at $60^{\circ} \mathrm{C}$ for $4 \mathrm{~h}$. The dried defatted residue dissolves in methanol $(\mathrm{w} / \mathrm{v})$ and filters through Whatman filter paper. $100 \mu \mathrm{l}$ of methanolic extracts were mixed with $2.5 \mathrm{ml}$ deionized water followed by the addition of $0.1 \mathrm{ml}(2 \mathrm{~N})$ Folin-Ciocalteu reagent. The mixtures were well stirred and allowed to stand for $6 \mathrm{~min}$ before $0.5 \mathrm{ml}$ of a $20 \%$ sodium carbonate solution was added. The color developed after $30 \mathrm{~min}$ at room temperature and the absorbance was measured at $760 \mathrm{~nm}$ using an ultraviolet-visible spectrophotometer. Phenolic content was expressed as milligram gallic acid equivalent per gram (mg GAE/g).

\section{FRS activity (DPPH assay)}

FRSactivity was determined by the method of Lee etal., 2003 [12]. $0.1 \mathrm{mM}$ DPPH was prepared in methanol. $1 \mathrm{ml}$ of this solution was added to $4 \mathrm{ml}$ leaves extract of different concentrations $(15-135 \mu \mathrm{g} / \mathrm{mL})$. The mixture was shaken vigorously and allowed to stand at room temperature for $30 \mathrm{~min}$ in dark and absorbance was measured at $520 \mathrm{~nm}$. A control reaction was carried out without plant extract. Percentage of radical scavenging activity was determined and compared with standards.

$$
\text { Percentage inhibition }=\frac{A c-\text { As }}{\text { Ac }} \times 100
$$

Where, Ac is the absorbance of the control and As is the absorbance of the sample.

\section{Statistical analysis}

The result obtained by this analysis was expressed as the average of triplicate determinations $(\mathrm{n}=3)$ along with their standard derivations (mean \pm standard deviation). Statistical comparisons were performed with one-way analysis of variance, and $\mathrm{p}<0.05$ was regarded as statistically significant. The correlation coefficients (R) between TPC and FRS activity were calculated to determine their relationship between them.

\section{RESULTS AND DISCUSSION}

TPC was evaluated using Folin-Ciocalteu reagent. The appearance of blue color due to the reduction of Folin-Ciocalteu reagent by extract indicates the presence of phenols. The TPC was expressed in terms of GAE. TPC was found high in methanolic extract $(6.2 \pm 0.01)$, followed by ethanol (6.1 $\pm 0.07 \mathrm{mg} \mathrm{GAE} / \mathrm{g}$ ), methanol $80 \%$ ( $4.9 \pm 0.05 \mathrm{mg} \mathrm{GAE} / \mathrm{g}$ ), acetone $(4.8 \pm 0.03 \mathrm{mg} \mathrm{GAE} / \mathrm{g})$, aqueous $(3.9 \pm 0.18 \mathrm{mg} \mathrm{GAE} / \mathrm{g})$, ethyl acetate $(3.1 \pm 0.01 \mathrm{mg} \mathrm{GAE} / \mathrm{g})$, and ethanol $80 \%(1.7 \pm 0.04 \mathrm{mg} \mathrm{GAE} / \mathrm{g})$.

Phenolic compounds are perhaps the largest group of phytochemicals that have shown disease preventing and health-promoting effects and have received the most attention among researchers largely due to their antioxidant activity [13-15]. It has been reported that long-term consumption of diets rich in plant polyphenols offered some protection against the development of cancers, cardiovascular diseases, osteoporosis, diabetes, and neurodegenerative diseases [16,17].

In recent years, natural antioxidants, particularly those present in fruits and vegetables, have gained increasing interests among consumers and the scientific community because dietary antioxidants are helpful in assisting the body to neutralize free radicals. Therefore, it is important to consume a diet high in antioxidants to reduce the harmful effects of oxidative stress [18-21].

FRS activity of various extracts of leaves was determined. The ability of leaves extracts to scavenge purple color of DPPH radical indicates its scavenging properties. The scavenging activity increases in a dose-dependent manner (Fig. 1). Higher inhibition concentration was observed in methanol (inhibitory concentration $50\left[\mathrm{IC}_{50}\right]=8.74 \mu \mathrm{g} / \mathrm{ml}$ ), followed by ethanol ( $\left.\mathrm{IC}_{50}=30.26 \mu \mathrm{g} / \mathrm{ml}\right)$, ethanol $80 \%\left(\mathrm{IC}_{50}=32.31 \mu \mathrm{g} / \mathrm{ml}\right)$, methanol $80 \%\left(\mathrm{IC}_{50}=55.16 \mu \mathrm{g} / \mathrm{ml}\right)$, acetone $\left(\mathrm{IC}_{50}=59.51 \mu \mathrm{g} / \mathrm{ml}\right)$, aqueous $\left(\mathrm{IC}_{50}=83.19 \mu \mathrm{g} / \mathrm{ml}\right)$, chloroform $\left(\mathrm{IC}_{50}=87.74 \mu \mathrm{g} / \mathrm{ml}\right)$, and ethyl acetate $\left(\mathrm{IC}_{50}=102.21 \mu \mathrm{g} / \mathrm{ml}\right)$. A good correlation $\left(\mathrm{y}=0.6265 \mathrm{x}+42.91 \mathrm{R}^{2}=0.9756\right)$

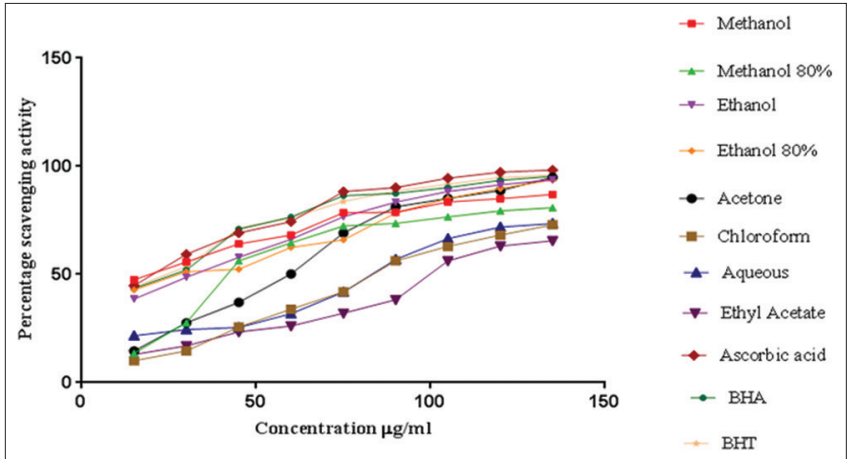

Fig. 1: Comparison of free radical scavenging activity of solvents, butylated hydroxyanisole, butylated hydroxytoluene, and ascorbic acid. The result is mean \pm standard deviation of three parallel measurements. $\mathbf{p}<\mathbf{0 . 0 0 5}$ when compared to control

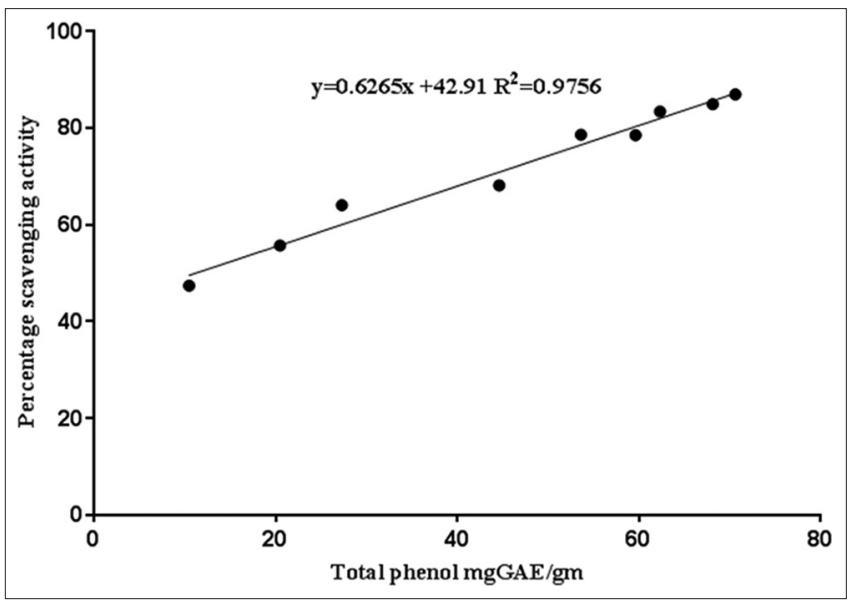

Fig. 2: Correlation between total phenolic content and free radical scavenging activity of methanolic extract of leaves

was also observed between TPC and FRS activity of methanolic extract (Fig. 2).

In earlier reports, leaves extract of M. elengi L. was reported to possess antioxidant activity [22-24]. Whereas, in the present study, we compared the content of phenols in a wide range of polar (Aqueous, methanol, ethanol, acetone, ethyl acetate) and non-polar (chloroform) solvents. Similarly, we scrutinized different polar and non-polar solvents for FRS activity at different doses $(15,30,45,60,75,90,105,120$, and $135 \mu \mathrm{g} / \mathrm{ml})$ and compared with standard ascorbic acid, BHA, and BHT (Fig. 1). The positive relationship indicates the role of phenols in defense against ROS.

\section{CONCLUSION}

In this work, all the eight extracts showed their role in defense against reactive free radicals. The study clearly showed that methanolic extracts possess significant FRS activity compared to other extracts and it is also a rich source of phenols, which can be used against ailments caused by free radicals.

\section{ACKNOWLEDGMENT}

Authors are thankful to the Head, Department of Botany, DDU Gorakhpur University, Gorakhpur, for providing necessary facilities.

\section{AUTHORS' CONTRIBUTIONS}

Both authors have designed and performed the experimental work in nutraceutical laboratory, Department of Botany, DDU Gorakhpur University, Gorakhpur. 


\section{CONFLICTS OF INTEREST}

The authors declare that they have no conflicts of interest.

\section{REFERENCES}

1. Alagumanivasagam G, Pasupathy R, Kottaimuthu A, Manavalan R. A review on in vitro antioxidant methods. Int $\mathrm{J}$ Pharm Chem Sci 2012;1:662-74.

2. Canadanovic-Brunet JM, Djilas SM, Cetkovic GS, Tumbas VT. Freeradical scavenging activity of wormwood (Artemisia absinthium L) extracts. J Sci Food Agric 2005;8:265-72.

3. Auddy B, Ferreira M, Blasina F, Lafon L, Arredondo F, Dajas F, et al. Screening of antioxidant activity of three indian medicinal plants, traditionally used for the management of neurodegenerative diseases. J Ethnopharmacol 2003;84:131-8.

4. Fatima Z, Abderrahmane A, Seddik K, Lekhmici A. Antioxidant activity assessment of Tamus Communis L. Roots. Int J Pharm Pharm Sci 2016;8:64-71.

5. Gülçin I, Küfrevioglu OI, Oktay $M$, Büyükokuroglu ME. Antioxidant, antimicrobial, antiulcer and analgesic activities of nettle (Urtica dioica L.). J Ethnopharmacol 2004;90:205-15.

6. Villaño D, Fernández-Pachón MS, Moyá ML, Troncoso AM, GarcíaParrilla MC. Radical scavenging ability of polyphenolic compounds towards DPPH free radical. Talanta 2007;71:230-5.

7. Prakasia PP, Nair AS. Evaluation of in vitro antioxidant potential of the total crude alkaloid extract of Glycosmis pentaphylla (Retz) Correa leaves. Inter J Pharm Pharm Sci 2016;8:85-91.

8. Beverly CD, Sudarsanam G. Ethnomedicinal plant knowledge and practice of people of javadhu hills in Tamil Nadu. Asi Paci J Trop Biomed 2011;1:79-80.

9. Tiwari AK. Indigenous knowledge for treating skin disease in some selected districts of Chhattisgarh (India). Int J Recent Sci Res 2015;6:2654-7.

10. Singh V, Pandey VN, Shukla K. Quantitative estimation of secondary metabolites from Mimusops elengi L. Int J Sci Eng Res 2017;5:13-5.

11. $\mathrm{Wu} \mathrm{T}$, Guan Y, Ye J. Determination of flavonoids and ascorbic acid in grapefruit peel and juice by capillary electrophoresis with electrochemical detection. Food Chem 2007;100:1573-9.

12. Lee SE, Hwang HJ, Ha JS, Jeong HS, Kim JH. Screening of medicinal plant extracts for antioxidant activity. Life Sci 2003;73:167-79.

13. Bravo L. Polyphenols: Chemistry, dietary sources, metabolism, and nutritional significance. Nutr Rev 1998;56:317-33.

14. Balasundram N, Sundaram K, Samman S. Phenolic compounds in plants and agri-industrial by-products: Antioxidant activity, occurrence, and potential uses. Food Chem 2006;99:191-203.

15. Pandey KB, Rizvi SI. Plant polyphenols as dietary antioxidants in human health and disease. Oxid Med Cell Longev 2009;2:270-8.

16. Choi CW, Kim SC, Hwang SS, Choi K, Ahn HJ, Lee MY, et al. Antioxidant activity and free radical scavenging capacity between Korean medicinal plants and flavonoids by assay-guided comparison. Plant Sci 2002;163:1161-8.

17. Do QD, Angkawijaya AE, Tran-Nguyen PL, Huynh LH, Soetaredjo FE, Ismadji S, et al. Effect of extraction solvent on total phenol content, total flavonoid content, and antioxidant activity of Limnophila aromatic. J Food Drug Anal 2014;2:296-302.

18. Temple NJ. Antioxidants and disease: More questions those answers. Nutrit Rese 2000;20:449-59.

19. Sun Y. Free radicals, antioxidant enzymes, and carcinogenesis. Free Radic Biol Med 1990;8:583-99.

20. Sireesha K, Raghunandan N. Preliminary phytochemical screening and antimicrobial activity of dried flowers of Adenium obesum. Int J Curr Pharm Res 2019;11:34-6.

21. Wiseman H, Halliwell B. Damage to DNA by reactive oxygen and nitrogen species: Role in inflammatory disease and progression to cancer. Biochem J 1996;313:17-29.

22. Karmakar UK, Sultana R, Biswas NN. Antioxidant, analgesic and cytotoxic activities of Mimusops elengi Linn. Leaves. Int J Pharm Sci Res 2011;2:2791-7.

23. Vinay KN, Lakshmi VV, Satyanarayan ND, Anantacharya R. In vitro antioxidant activity of leaf solvent extracts Mimusops elengi Linn. J Med Plant Stud 2016;4:84-7.

24. Saha MR, Hasana SM, Aktera R, Hossaina MM, Alam MS, Alam MA, et al. In vitro free radical scavenging activity of methanol extract of the leaves of Mimusops elengi Linn. Bangl J Vet Med 2008;6:197-202. 